\title{
REFINED GRID REGIONAL MODELLING OF ACIDIC AND MERCURY DEPOSITION OVER NORTHEAST US AND THE CONTRIBUTION OF THE NEW YORK POWER SECTOR
}

\author{
L. SEDEFIAN ${ }^{1}$, M. KU ${ }^{2}$, K. CIVEROLO ${ }^{2}$, W. HAO ${ }^{2} \&$ E. ZALEWSKY ${ }^{2}$ \\ ${ }^{1}$ Sedefian Consulting, Malta, NY, USA \\ ${ }^{2}$ New York State Department of Environmental Conservation, Albany, NY, USA
}

\begin{abstract}
Current implementations of federal and state regulations have relied heavily on regional-scale photochemical models which, however, reflect outdated emissions and have a level of uncertainly due to the coarse grid resolution used in typical applications. The purpose of this study is to refine the $12 \mathrm{~km}$ grid resolution from recent assessments to a $4 \mathrm{~km}$ grid level in a novel application of the Community Multiscale Air Quality (CMAQ) modelling system on an annual timescale. The main incentive was to determine the total acidic and mercury deposition over New York State (NYS) and the contribution of the NYS power sector point sources. To that end, the latest available United States Environmental Protection Agency's (USEPA) National Emissions Inventory (NEI) for 2011 and Weather Research Forecast (WRF) simulated meteorological data were generated on the $4 \mathrm{~km}$ grid domain over the Northeastern United States centred on NYS. For mercury, emissions of the elemental, oxidized and particulate species were characterized for source categories to allow for species-dependent wet removal factors and dry deposition velocities. The results for mercury deposition indicate very low contributions from all NYS, but showed the importance of the oxidized $\mathrm{Hg}$ from both wet and dry components. The impacts of $\mathrm{Hg}$ emissions outside the modelling domain were found to clearly dominate total depositions in NYS. For acidic deposition, the wet component controlled for sulphate, while for total sulphur and nitrates, dry deposition had a significant contribution. For the NYS power sector, the only large contribution was due to dry deposition of $\mathrm{SO} 2$ for total sulphur. The projected total wet depositions of sulphate, nitrate and mercury compare very favourably with observed levels at National Atmospheric Deposition Program (NADP) sites.

Keywords: acidic and mercury deposition, CMAQ model, EGUs and WTEs, emission inventory, refined grid, regional modelling, power production sources
\end{abstract}

\section{INTRODUCTION}

Recent USEPA and NYS regulatory approaches have emphasized the interaction of multipollutant mixtures due to a shift brought about by requirements to reduce toxics such as mercury from power plants by EPA's Mercury and Air Toxics (MATS) rule [1] and the reinstatement of USEPA's Cross-State Air Pollution Rule (CSAPR) [2]. These rules affect reductions in regional-scale emissions of sulphur oxides (SOx), nitrogen oxides (NOx) and mercury $(\mathrm{Hg})$. These regulatory requirements have been supported by technical documents relying heavily on regional photochemical modelling assessments which affect emissions from energy production sources such as energy generation units (EGUs) and waste-to-energy (WTE) facilities.

However, technical assessments for these requirements have not been commensurate with the latest emissions data and the techniques necessary to properly assess their implementation. To date, the assessments have relied upon outdated modelling simulations, including past emission inventories and relatively coarse meteorological and modelling grid data. The latter limitation has not allowed the proper resolution of the influence of the landscape on the wind fields, especially in complex terrain, while dry and wet deposition have not been 
resolved at the scale of biological 'hot spots'. Thus, there is a clear need to update the technical foundations to assess deposition of inorganic pollutants.

Germane to the current study is the recognition that modelling studies have not fully quantified current and future contributions of New York's power generation sector to the regional acidic and mercury deposition. In addition, although elemental mercury has been identified to comprise well over $90 \%$ of total ambient mercury, the emissions from the power production sector have been found to comprise an even mix of the elemental versus divalent/ particulate species. Furthermore, there has been a recent shift in the fuel use in the EGU sector in and around NYS from coal to natural gas and low-sulphur oil, and the implications of this shift need to be fully understood. Answers to these issues can be addressed practically by regional modelling assessments as states in the eastern part of the United States implement mandated CSAPR reductions in $\mathrm{SO}_{2}$ and $\mathrm{NOx}$ emissions. Directly related to the deposition levels is preparatory work for USEPA's revisit to the secondary ambient air quality standard for SOx and NOx since USEPA's previous documentation established aquatic acidification as an indicator of detrimental effects. However, no updated acidic deposition modelling simulations or assessments of the consequences of $\mathrm{Hg}$ emissions reductions are forthcoming from USEPA. This study attempts to answer some of the issues of importance to NYS through an updated regional modelling assessment.

\section{PREVIOUS REGIONAL MODELLING FINDINGS}

The applications of photochemical transport and dispersion models as the basis of the technical support of regulatory actions have evolved considerably over decades based on field research, computational improvements and model performance exercises. These changes have allowed for refinements to the chemical processes, the meteorological data inputs and horizontal and vertical resolutions which were previously not considered practical. This study aims to use the latest technical developments in EPA's CMAQ modelling system to determine deposition estimates from an updated national emissions inventory and from refined data for NYS major point sources. It is informative to first provide examples of pertinent previous analyses which have formed the basis of regulatory actions by USEPA and NYS. A noteworthy acidic deposition analysis was conducted for the first time in the nation's regulatory action to reduce its precursor emissions, i.e. the NYS Acidic Deposition Control Act (SADCA) in 1985. A long-term regional statistical model was used to determine areawide emissions contributions to impacts on NYS receptors based on a crude $100 \mathrm{~km}$ spatial resolution and 12 hours' incremental wind and precipitation fields. A number of federal regulatory initiatives followed, including the acid rain programme with the application of a regional model for dry deposition of sulphates in combination with observed wet deposition levels. Concurrently, the CMAQ modelling approaches were being enhanced and the USEPA performed a number of model evaluation studies to assure the simulations performed for regulatory purposes were technically acceptable (e.g. Appel et al. [3]). The model was driven by both a $36 \mathrm{~km}$ and a $12 \mathrm{~km}$ grid 5th Generation Mesoscale Model (MM5) meteorological data with emissions data based on 'adjusted' 2002 NEI to simulated wet acidic deposition. A comparison to observed data was good, but with adjustments using observed precipitation data. More recently, Dennis and Foley [4] used another updated version of CMAQ simulations over the United States during 2002-2011, including the use of WRF simulations, updated land use characteristics and emissions estimates. Comparisons to annual wet deposition observations indicated very good agreements for at least the eastern United States (i.e. errors of less than 20\%). It was also noted that CMAQ model estimates of oxidized nitrogen 
and sulphur deposition showed higher dry than wet annual values. Thus, data made available by NADP include total deposition based on an assessment by Schwede and Lear [5] using CMAQ simulations of hourly dry deposition using observed concentrations, coupled with observed wet deposition for 2002-2011. A $36 \mathrm{~km}$ grid and MM5 meteorology were used in 2002-2006; however, $12 \mathrm{~km}$ grid and WRF meteorology were used in 2007-2011. Dry deposition for $\mathrm{SO}_{2}$ was found to be more important than for sulphates due to its higher dry deposition velocity, while for nitrogen, dry deposition of the nitric acid $\left(\mathrm{HNO}_{3}\right)$ was determined to be of most importance.

For mercury deposition, USEPA performed regional-scale $\mathrm{Hg}$ modelling for the United States in the 1997 USEPA Mercury Report to Congress [6] using a $40 \mathrm{~km}$ grid and which recognized the importance of separately treating the three species of mercury due to significant differences in their deposition factors. It also included a mechanism of indirect deposition of elemental $\mathrm{Hg}$ by inter-species chemical transformations. Subsequently, CMAQ was tested by USEPA and NYS Department of Environmental Conservation (NYSDEC) with enhanced features for mercury as part of a comprehensive study by Bullock et al. [7] using the 2001 NEI and MM5 meteorological data to predict depositions over a $36 \mathrm{~km}$ grid. CMAQ was used to assess mercury deposition for national regulatory initiatives, e.g. the Clean Air Mercury Rule (CAMR) with wet deposition projections showing underestimation of observations in the eastern United States by $23 \%$, but overestimated values in the west. Subsequently, CMAQ was also used for the assessment of $\mathrm{Hg}$ for the MATS rule for coal and oil power plants. Mercury emissions were updated to the 2005 NEI and used with 2005 MM5 meteorology over a $12 \mathrm{~km}$ grid nested within in a $36 \mathrm{~km}$ grid. An evaluation against wet deposition found overestimations in three of the four quarters of the year as opposed to the underestimation for CAMR.

A modelling study most germane to the current study was performed specifically for the northeast states and identified NY-specific emission sector impacts. The Mercury Modeling Study [8] in 2007 used yet another regional-scale model with the specific goal of apportioning the contribution to deposition by source regions and major source categories. The meteorological data used was EPA's MM5 runs for 1996 over a $36 \mathrm{~km}$ grid with 1999 and 2002 emissions from point, area and mobile sources. The modelling results showed the importance of the WTE combustors located in the northeast as a major contributor to depositions in 1996, while for the 2002 inventory results, these WTE impacts dropped considerably in association with emissions reductions from this source category. The results also indicated the dominance of $\mathrm{Hg}$ emissions outside of the northeast region, including coal burning EGUs and continental scale emissions.

\section{MODELLING METHODOLOGIES}

Guided by previous modelling results, the CMAQ model (v. 5.0.2) was chosen to not only simulate the complex set of source interactions and meteorological conditions, but also to properly account for source attributions from NYS and outside the modelling domain. CMAQ and its processors were applied at a refined $4 \mathrm{~km}$ horizontal grid scale to generate seasonal and annual deposition averaging and the contribution of the wet and dry components. The CMAQ modelling system [9] contains three modelling components: a meteorological modelling system to simulate atmospheric parameters and wind flow conditions, an emission module for projecting man-made and natural emissions, and a chemistry-transport module for chemical transformation of the fate of pollutants. Since average impacts are determined within each grid cell, the smaller areas of the $4 \mathrm{~km}$ grid are expected to produce more detailed features. The $4 \mathrm{~km}$ and the outer nested $12 \mathrm{~km}$ grids are shown in Fig. 1. 


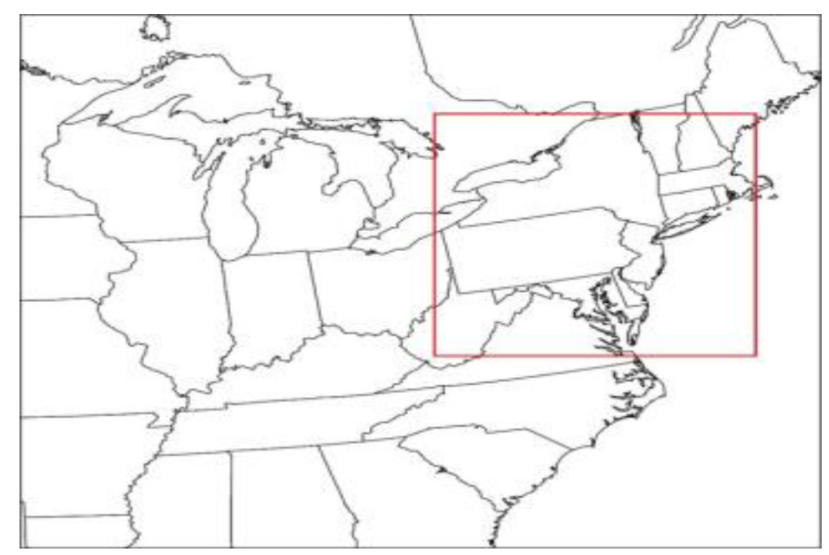

Figure 1: The $12 \mathrm{~km}$ grid and the nested refined $4 \mathrm{~km}$ grid (inner box).

The current preferred meteorological model, WRF (v. 3.6.1), was used to simulate hourly horizontal and vertical fields of spatially varying dynamic and static parameters over the $4 \mathrm{~km}$ grid. WRF simulations incorporate all observed data from National Weather Station (NWS) sites and precipitation network data in the domain. It was found that data for March 2011 contained inordinate number of missing hours and, thus, annual accumulated deposition was calculated only over the remaining 11 months of data. An important factor for meteorological and deposition simulations is the land use data which for the WRF-CMAQ interface used the 2006 NLCD. Based on initial simulations for two summer months, it became clear that for proper precipitation modelling, which controls wet deposition, the cloud subgrid scheme should invoke the convective module for not only the coarser $12 \mathrm{~km}$ but also the $4 \mathrm{~km}$ cases.

Through its aerosol module, CMAQ calculates the fate of inorganic gases through thermodynamic equilibrium between the gas phase and fine particle modes using the latest methods in ISORROPIA II. This revised chemistry includes the crustal aerosol components in the multiple reactions or equilibria by considering deliquescence of the mixtures. The emissions processor used to message the large set of data from the 2011 NEI for input to CMAQ is the Sparse Matrix Operator Kernel Emissions (SMOKE) system. SMOKE input data consist of emissions inventories, temporal and chemical speciation profiles, spatial surrogates, gridded meteorology and land use. The processor keeps track of the various source types and performs rudimentary checks of the parameters.

The basic deposition methods used in the CMAQ model rely on essentially the relationships between concentrations and the resultant deposition due to dry and wet processes and the parameters which control these processes. A summary is provided for gaseous and particulate deposition methods in documents such as Wesley et al. [10]. The applications of the methods invoke certain assumptions in the formulations and specific pollutant physical and chemical properties. For the dry approach, the calculation is performed for each hour of meteorology with deposition flux (Fd) as the product of ambient concentration $(\mathrm{Cd})$ and dry deposition velocity $(\mathrm{Vd})$ from $\mathrm{Fd}=\mathrm{Cd} \times \mathrm{Vd}$, where $\mathrm{Vd}$ is calculated as an analogy to resistance to deposition using an inverse relationship. The importance of the underlying 
conditions is highly dependent on whether the pollutant is in gaseous or in particulate form and involves the aerodynamic resistance using surface layer similarity parameters and the surface resistances to uptake. The deposition of gases and particles due to wet processes is essentially a function of the precipitation in the column through which it encounters the pollutant concentrations. For gases $\mathrm{Fg}=10^{-3} \rho_{\mathrm{g}} \mathrm{Wgr}$, where $\mathrm{Wgr}$ is the washout ratio and depends on Henry's law constant. Wet deposition for particles is calculated by an analogous equation with distinct washout ratios.

\section{EMISSIONS INVENTORY AND POWER SECTOR SOURCE REVISIONS}

One of the more important, but at times overlooked, inputs to a modelling exercise is the accuracy of the set of emissions sources and the corresponding emission rates and stack parameters. Emission inventory development is a resource-intensive and somewhat tedious task, and its quality depends on factors such as reporting requirements. For example, data on the acidic deposition precursors $\mathrm{SO}_{2}$ and $\mathrm{NOx}$ from larger point sources are monitored and reported on an hourly basis by the power industry, but there are no such requirements for ammonia $\left(\mathrm{NH}_{3}\right)$ or mercury $(\mathrm{Hg})$ on a sector-wide scale. Thus, one of the major tasks of the current study was to review the data for the specific set of sources in NYS to be tracked by the CMAQ model for their relative contributions to deposition. These sources, however, are a small fraction of the sources in the EPA 2011 NEI (v.2.0) used for the modelling.

The starting point of identifying major point sources of acidic precursors and mercury were reports and data sets available to NYSDEC from 2009 to 2011. These data were augmented with source-specific stack test reports and other assessments. A potential initial set of three dozen EGU and WTE facilities were identified, but it became clear that mercury emissions were also significant from other source types such as cement plants and steel production. Detailed data comparisons and reviews were performed for these large point sources which resulted in a final set of 38 facilities to be tracked by CMAQ, as depicted in Fig. 2. Of these, 26 were large $\mathrm{Hg}$ emitters and the review resulted in a downward revision of $25 \%$ in annual $\mathrm{Hg}$ emissions. The Hg subset of WTEs, coal burning EGUs and an 'other' category contributed 17, 19 and 64\%, respectively, to the rather small total emissions of $334 \mathrm{~kg} / \mathrm{yr}$. For the acidic deposition precursors $\mathrm{SO}_{2}$ and NOx, the relative contribution from the EGUs was over $90 \%$ of all NYS point sources and included gas burning EGUs not in the Hg list. Ammonia emissions were also modelled from these sources, but these were very low in comparison to the dominant agricultural activities.

A summary of 2011 NEI mercury emissions from all source categories in NYS also indicated significant contributions from certain area sources confined to the New York City area, some of which were overstated and were adjusted using data on $\mathrm{Hg}$ in fuels. An important issue especially for the large $\mathrm{Hg}$ point sources was the relative emissions of the three species of $\mathrm{Hg}$ which have very different deposition profiles. Data from national stack tests on EGUs and WTEs and technology based estimates for others were used to assigned percentages to the species. Elemental mercury missions were the largest for the EGU and 'other' source categories, while oxidized Hg dominated the WTE emissions. The emissions of the tracked NYS large sources tracked were $90 \%$ of the total $\mathrm{Hg}$ and about half of the $\mathrm{SO}_{2}$ and NOx emissions from all NYS point sources. However, the emissions from all NYS sources were found to be about $10 \%$ of the total domain emissions for $\mathrm{Hg}$ as well as for $\mathrm{SO}_{2}$ and $\mathrm{NOx}$. 


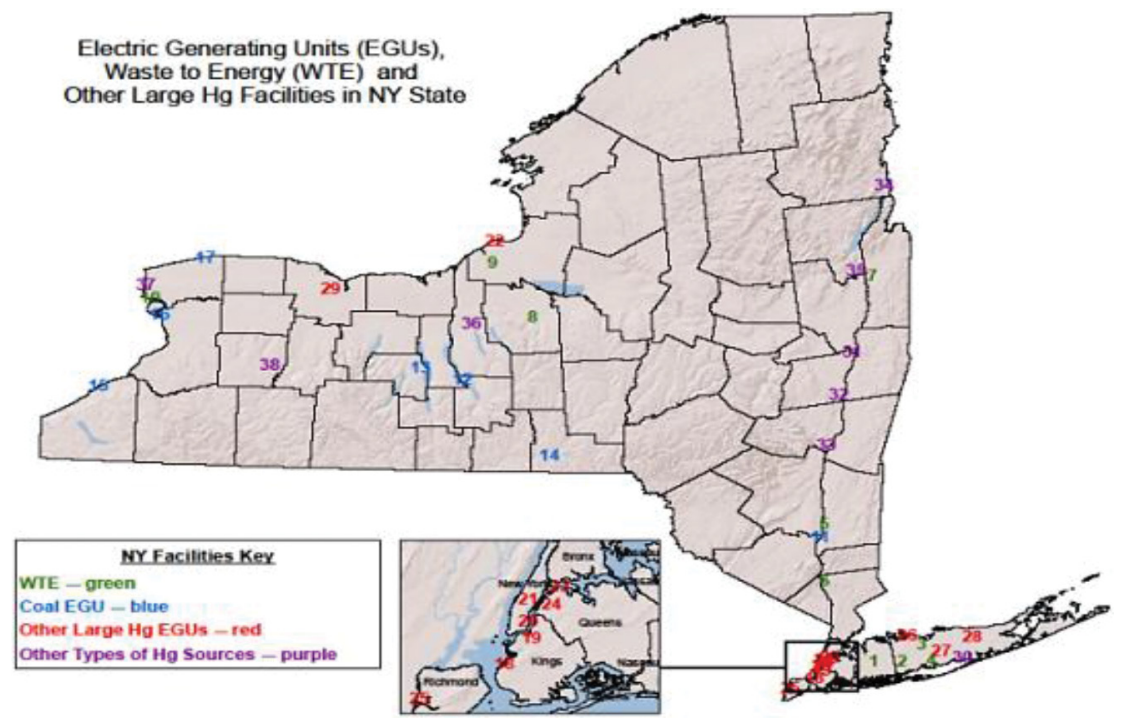

Figure 2: Locations of the set of large point sources in NYS tracked in CMAQ.

\section{CMAQ DEPOSITION RESULTS AND DISCUSSIONS}

Here we present examples of the overall results to be made available in a final report. The first item considered was whether the $4 \mathrm{~km}$ grid resolution provided more spatial details for both the input parameters, such as terrain and precipitation, and the consequent deposition. An example for precipitations is shown in Fig. 3 which seems to indicate better resolved WRF simulations over the $4 \mathrm{~km}$ grid. Similar findings were noted in the ability of the finer $4 \mathrm{~km}$ grid to better identify significant terrain features over NYS and in corresponding wet deposition fields.

To guide the application of CMAQ over the $4 \mathrm{~km}$ domain for the annual averages, preliminary modelling was performed using summer months of meteorological data over the $12 \mathrm{~km}$ and $4 \mathrm{~km}$ grids. This resulted in the decision to use the convective subgrid cloud component in WRF as noted previously. In addition, data for mercury emissions outside the modelling
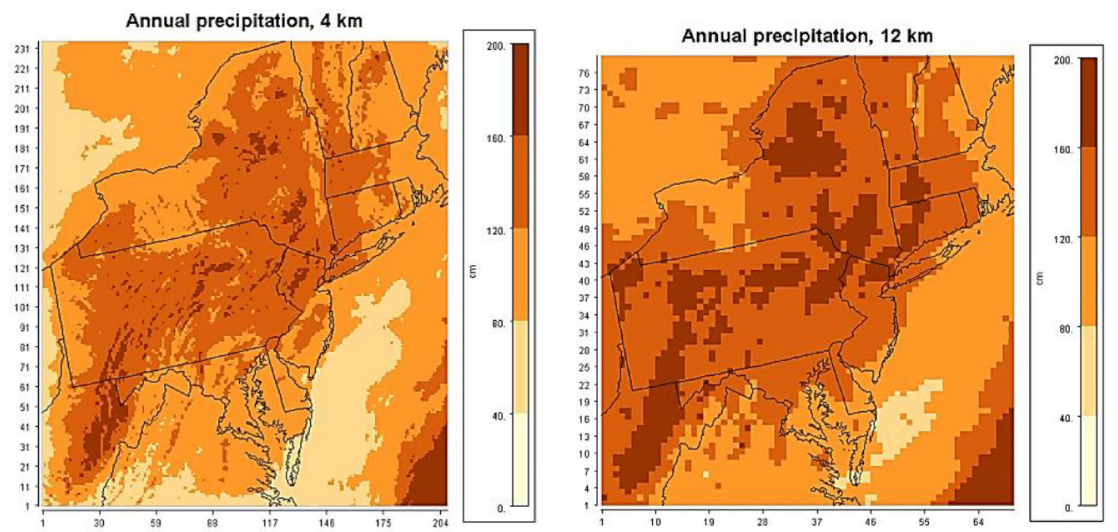

Figure 3: WRF simulated precipitation on the $4 \mathrm{~km}$ (left) and $12 \mathrm{~km}$ (right) grids. 
domain were not readily available in the 2011 NEI compared to the other pollutants. Thus, initial modelling performed without these source emissions indicated a clear underestimation of observed wet deposition. Thus, EPA data were processed for sources outside the domain and modelled as boundary conditions (BC). In addition, the recent option in CMAQ, which accounts for reemissions of mercury back to the atmosphere (bidirectional flux, or Bidi), was invoked in the initial modelling using June and July data over the $12 \mathrm{~km}$ grid. The results with and without the BC and Bidi options are presented in Fig. 4. It is clear that, first, the Bidi option does not affect the results to any extent, and, second, that the inclusion of the outside the domain sources is critical in properly estimating the observed wet $\mathrm{Hg}$ deposition at monitors in the domain. That is, Hg impacts in the domain from all of NYS sources and, in fact, due to all of the in-domain sources were a small fraction of the overall deposition when all sources outside of the domain were included as influx of mercury. This result is in keeping with previous findings and further CMAQ modelling included the BC input.

CMAQ modelling was performed for the full 2011 NEI as the base case and for another 'zero-out' case where the set of NYS large point sources were removed from the 2011 inventory. The difference between the two runs allowed the determination of the influence of the NYS sources which essentially represent the power sector for acidic deposition, plus certain other sources such as cement plants for mercury. Acidic deposition was calculated for all species including total sulphur (TS) which was calculated as sulphate plus $1.5 * \mathrm{SO}_{2}$. $\mathrm{Hg}$ deposition was determined for its species as well as for the total of all three.

It should be clarified that all deposition levels are the accumulated values over the timescales of interest. As examples, CMAQ predictions of annual total (wet plus dry) sulphate $\left(\mathrm{SO}_{4}\right)$, TS, plus total (THG) and oxidized $\left(\mathrm{Hg}_{2}\right)$ mercury deposition over the domain due to the base case $2011 \mathrm{NEI}$ are presented in Fig. 5. The $\mathrm{SO}_{4}$ results (in $\mathrm{kg} / \mathrm{ha}$ ) were found to be dominated by the wet component and are maximized in western Pennsylvania (PA) as a result of upwind/local emissions transport. The spatial variation in NYS is also attributed mainly to influx of wet deposition at smaller, yet significant, levels. As expected, the deposition of TS is enhanced by the inclusion of $\mathrm{SO}_{2}$ deposition and is found to be controlled by the dry component. For total $\mathrm{Hg}$ (in ug $/ \mathrm{m}^{2}$ ), which includes the elemental and oxidized forms, a similar pattern of the location of maxima is evident, but with broader spatial spread over NYS. The oxidized form of mercury $\left(\mathrm{Hg}_{2}\right)$ has the largest contribution to the total (THG), with the

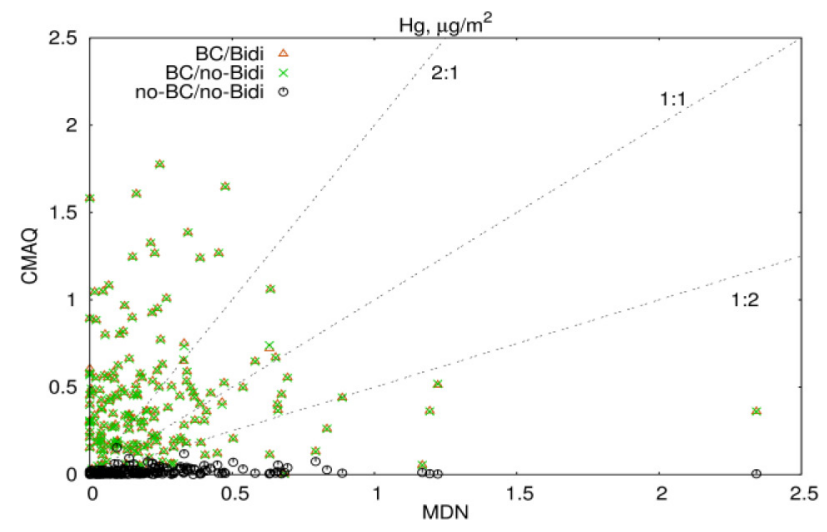

Figure 4: Observed and CMAQ weekly wet $\mathrm{Hg}$ deposition for June-July at 27 NADP sites with: BC/Bidi, BC/no-Bidi, and no-BC/no-Bidi. 

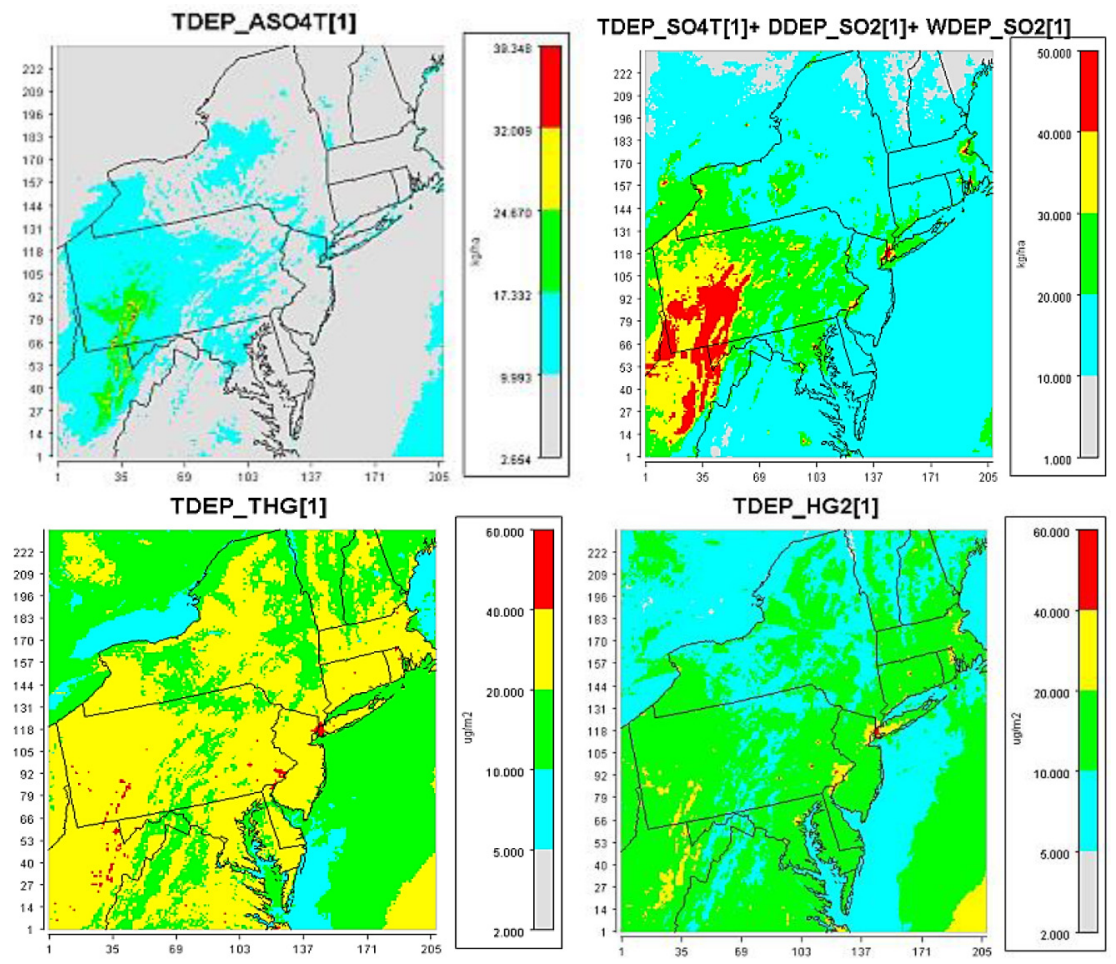

Figure 5: Deposition of total sulphate (top left), total sulphur (top right), total $\mathrm{Hg}$ (bottom left) and oxidized $\mathrm{Hg}$ (bottom right) due to the 2011 NEI base case.

elemental form contributing less due to its much lower deposition velocity and insolubility which counteract the higher emissions from this form. It was found that total $\mathrm{Hg}$ deposition was contributed by both the wet and dry components. The highest overall impacts are likely due to upwind sources, specifically coal-burning EGUs due to their dominant emission. The relatively high impacts in the New York City area are due to higher $\mathrm{Hg}$ emissions from area sources such as metal processing.

An important purpose of the study was to determine the contribution from NYS large point sources (i.e. power sector) to the overall levels of acidic and mercury deposition. As noted, these contributions were determined by an additional CMAQ run where the NYS large sources were 'zeroed out' of the 2011 NEI. The difference between the base case minus this 'zero out' case, the result divided by the base case, represents the fractional contribution of the NYS large sources to the overall impacts.

The results for total sulphur (TS) and for total $\mathrm{Hg}$ are depicted in Fig. 6. The inclusion of $\mathrm{SO}_{2}$ and its dry deposition is responsible for the relatively large local and also broader effects in acidic deposition (up to one third reductions) seen around the NYS sources omitted in the 'zero out' case. Figure 3 indicates these to be essentially the coal-burning EGUs. On the other hand, the large NY sources contribute little to the overall mercury impacts, with very limited areas of 'reductions' above 10\% around the coal-burning EGUs and cement plants. The corresponding results for sulphate and nitrate are even less prominent than the mercury result, indicating the low contribution of the NYS point source subset to the overall deposition 
( SO4T[1]+ SO2T[1]-SO4T[2]-SO2T[2])/(SO4T[1]+SO2T)
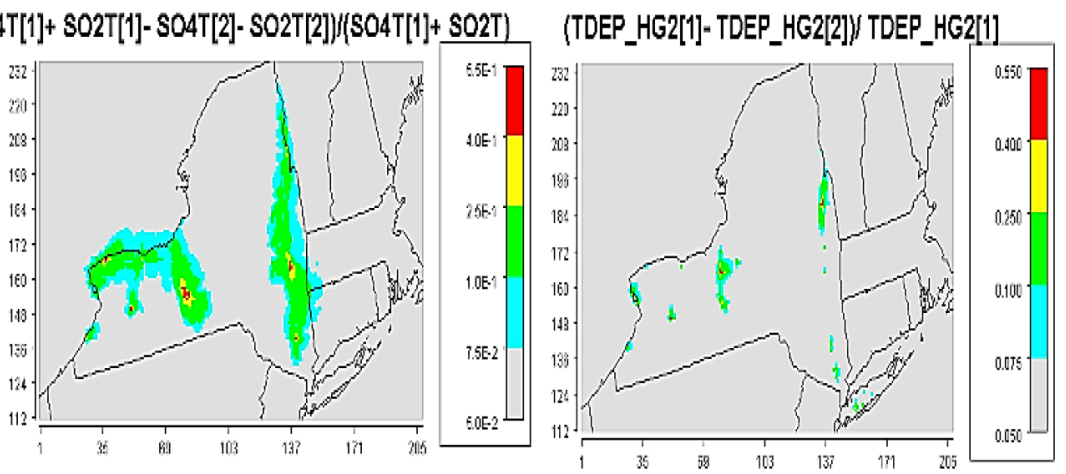

Figure 6: The contribution of NY large point sources relative to the total sulphur (left) and total $\mathrm{Hg}$ (right) deposition.

levels. It is important to note that a large number of the NYS point sources in the 2011 NEI included in the CMAQ 'tracking' have since either eliminated or greatly reduced coal use or undergone modernization.

It is also important to assure that model simulations adequately represent observed levels to be able to use the former for policy decisions. Seasonal CMAQ predictions of wet deposition of sulphate and WRF simulations of precipitation are compared to available observations at monitors throughout the modelling domain from 47 NADP sites in Fig. 7. The CMAQ to observed comparison for nitrate and $\mathrm{Hg}$ are is strikingly similar to the $\mathrm{SO}_{4}$ deposition results. These comparisons indicate a general underestimation by CMAQ for all acidic deposition and $\mathrm{Hg}$ species on an annual level which is driven by the clear underestimation during the summer and, secondarily, by the spring results. Comparisons during the fall and winter seasons appear to be much better. Although it is found that the wet deposition underestimation is mainly related to the corresponding finding for precipitation, the correlation indicated that this is not the only determinant. Calculated normalized mean error (NME) and bias (NMB) indicate that on an annual basis, CMAQ simulations are all within $30 \%$ of observations, with the lowest NME of $15.8 \%$ and NMB of $-6.5 \%$ for mercury which is somewhat surprising given the uncertainty in the $\mathrm{Hg}$ emissions inventory. From the standpoint of the modelling community, these results are remarkably good. Thus, such modelling can serve the needs of regulators.
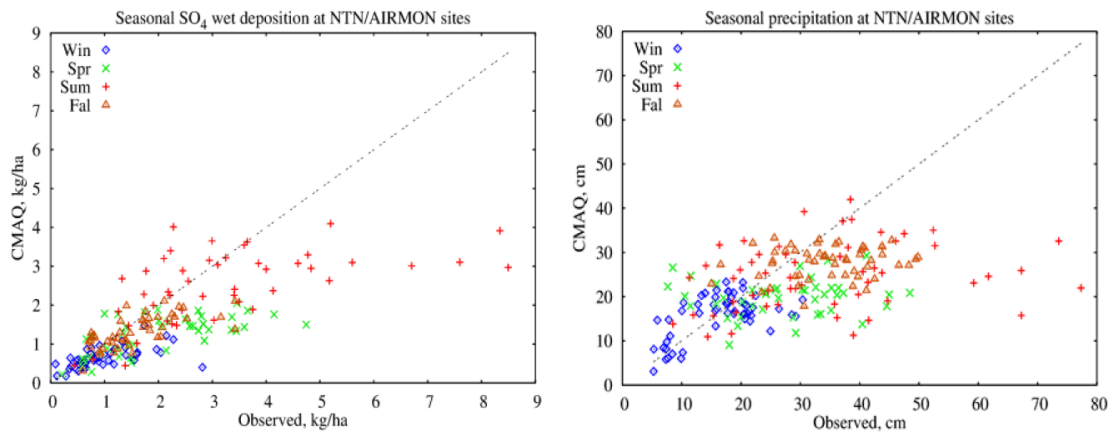

Figure 7: Seasonal sulphate and precipitation comparisons of CMAQ projections to NADP observations. 


\section{CONCLUSION}

A regional modelling study was conducted for Northeastern United States centred on NYS to determine acidic and mercury deposition over a refined $4 \mathrm{~km}$ grid. The latest versions of the USEPA CMAQ and WRF models were used with emissions from the 2011 national inventory to project total deposition of various species and the contribution from major NYS sources to these levels. It was found that NYS sources contributed minimally to the overall impacts, except for total sulphur, for which the major point sources had a relatively large, but localized, effect from $\mathrm{SO}_{2}$. The $4 \mathrm{~km}$ grid CMAQ results compare favourably to observed wet deposition levels at monitors throughout the modelling domain.

\section{ACKNOWLEDGEMENTS}

This research was funded by a grant from NYSERDA and supported by NYSDEC who do not necessarily endorse the study findings or conclusions.

\section{REFERENCES}

[1] EPA's MATS Rule, available at http://www.epa.gov/mats/actions.html (accessed 17 March 2016)

[2] EPA's CSAPR Rule, available at http://www.epa.gov/airtransport/CSAPR/index.html (accessed 27 May 2016)

[3] Appel, K.W., Foley, K.M., Bash, J.O., Pinder, R.W., Dennis, R.L., Allen, D.J. \& Pickering, K., A multi-resolutions assessment of the Community Multiscale Air Quality (CMAQ) model v4.7 wet deposition estimates for 2002-2006. Geoscientific Model Development, 4, pp. 357-371, 2011. DOI: 10.5194/gmd-4-357-2011-supplement

[4] Dennis, R. \& Foley, K., Characteristics of new CMAQ Deposition series for 2002 to 2011 for critical loads. Presented at 2014 NADP Annual Meeting and Scientific Symposium, Indianapolis, Indiana, 23 October 2014.

[5] Schwede, D. \& Lear, G.G., A novel hybrid approach for estimating total deposition in the United States. Atmospheric Environment, 92, pp. 207-220, 2014. DOI: 10.1016/j. atmosenv.2014.04.008

[6] EPA Mercury Study Report to Congress. Volume III (1997). http://www.epa.gov/ttn/ oarpg/t3/reports/volume3.pdf (accessed 17 March 2016)

[7] Bullock, O.R., et al., An analysis of simulated wet deposition of mercury from North American Mercury Inter-comparison Study. Journal of Geophysical Research, 114(DO8301), pp. 1-12, 2009. DOI: 10.1029/2008JD011224

[8] NESCAUM (2007). Modeling Mercury in the Northeast United States. Report Dated October 2007, available at http://www.nescaum.org/topics/mercury (accessed 27 May 2016)

[9] See: https://www.cmascenter.org/download.cfm (accessed November 2016).

[10] Wesley, M.L., Doskey, P.V. \& Shannon, J.D., available at http://www3.epa.gov/ttn/ scram/dispersion_prefrec.htm\#aermod, 2002 